Journal of Engineering and Applied Sciences 14 (Special Issue 6): 9345-9351, 2019

ISSN: 1816-949X

(C) Medwell Journals, 2019

\title{
Effect of Thickness on Structural, Optical and Sensing Properties of CdS Thin Films Prepared by Ultrasonic Nebulizer Method
}

\author{
Salah Q. Haza'a and Hiba R. Shaker \\ Department of Physics, College of Education, Al-Mustansiriyah University, Baghdad, Iraq \\ Salehhazaa@yahoo.com
}

\begin{abstract}
Thin films of cadmium sulfide with different thickness $(300-600 \mathrm{~nm})$ were deposited on preheated glass substrates $\left(430^{\circ} \mathrm{C}\right)$ by Ultrasonic Nebulizer Deposition (UND). The effect of thickness on the structural, optical and gas sensing properties of films has been investigated. X-ray diffraction patterns indicated that the CdS films had a polycrystalline hexagonal structure with preferred orientations along (002) and (101) directions. The crystallite size increases along (002) plane with the thickness increase and attains a maximum $56.68 \mathrm{~nm}$ for $600 \mathrm{~nm}$. The surface roughness is decreased with the increase of the films thickness which has been investigated by Atomic Force Microscopy (AFM). It was observed that as the film thickness increases from $300-600 \mathrm{~nm}$ the optical band gap blue shifted from $2.35-2.42 \mathrm{eV}$. The sensing characteristics of the films were studied as a function of operating temperature and for three different concentration $(10-30 \mathrm{ppm})$ of ethanol. The results showed that the sensitivity increases with operating temperature and reached a maximum values $75 \%$ at $310^{\circ} \mathrm{C}$ for the film with $500 \mathrm{~nm}$ thicknesses. Moreover, the films showed fast response and recovery times at higher operating temperature.
\end{abstract}

Key words: $\mathrm{CdS}$, thin films, ultrasonic nebulizer technique, gas sensors, hexagonal structure, AFM

\section{INTRODUCTION}

Cadmium sulfide is an 2-4 groups semiconductor it has been used as a suitable window layer, solar cells, photo detectors, lasers and gas sensors (Li et al., 2017; Mathew et al., 2004; Williams et al., 2014). This is because $\mathrm{CdS}$ thin films have high transparency, wide and direct bandgap transition $(2.42 \mathrm{eV})$, high electron affinity and n-type conductivity (Mathew et al., 2004; Williams et al., 2014; Chander and Dhaka, 2017). Different methods have been used to prepare CdS thin films which include $\mathrm{RF}$ sputtering (Williams et al., 2014), electron beam vacuum evaporation (Chander and Dhaka, 2017), Chemical Bath Deposition (CBD) (Kumar et al., 2009), physical evaporation (Nesheva et al., 2006).

Polycrystalline CdS based gas sensors are commercially important for detecting reducible gases such as hydrogen, methane, butane ethanol and ammonia with high sensitivities. It is well known that the gas adsorption onto the surface of a semiconductor can influence its electrical conductivity. In fact, conductivity of semiconductor gas sensor changes by few orders of magnitude with respect to initial value in the presence of gas concentrations up to few ppm in air at ambient pressure (Raut et al., 2013).
In this study, ultrasonic nebulizer method was used for fabricating CdS thin films, the purpose of this research was to investigate the effect of film thickness on structural, optical and gas sensing properties of CdS thin film.

\section{MATERIALS AND METHODS}

Experimental details: Cadmium sulfide films were deposited onto preheated glass slides $\left(430^{\circ} \mathrm{C}\right)$ with different thickness by Ultrasonic Nebulizer Deposition (UND) technique. Cadmium Chloride salt $\left(\mathrm{CdCl}_{2} \cdot 2 \mathrm{H}_{2} \mathrm{O}\right.$, $234.644 \mathrm{~g} / \mathrm{mol}(99.98 \%)$ pure BDH Chemical Ltd Pool England) and thiourea $\left(\mathrm{CS}\left(\mathrm{NH}_{2}\right)_{2}\right) 76.12 \mathrm{~g} / \mathrm{mol}, 99 \%$ pure, $\mathrm{BDH}$ Chemical Ltd Pool England) were dissolved in distilled water. The precursor solution of cadmium sulfide films was prepared by mixed aqueous solution (1:1) of cadmium chloride salt $(0.2 \mathrm{M})$ and aqueous solution of thiourea $(0.2 \mathrm{M})$ to make a $0.2 \mathrm{M}$ solution of total metal content. The resulting solution was sprayed onto heated glass substrates using an ultrasonic nebulizer system (Sonics) which transformed the liquid to a steam. In order to get good quality films and complete combustion all the deposition parameters

Corresponding Author: Salah Q. Haza'a, Department of Physics, College of Education, Al-Mustansiriyah University, Baghdad, Iraq,Salehhazaa@yahoo.com 
such as the distance between the substrate and the nozzle, gas flow rate, deposition temperature and the concentration of the solutions were optimized.

Film thickness (t) measured by weight difference method and optical interferometer method. The optical method was based on interference of $\mathrm{He}-\mathrm{Ne}$ laser light beam reflected from film surface and substrate bottom by using the known Eq. 1:

$$
\mathrm{t}=\frac{\Delta \mathrm{x}}{\mathrm{x}} \times \frac{\lambda}{2}
$$

Where:

$\mathrm{x}=$ The fringe width

- $\mathrm{x}=$ The distance between two fringes

- $\quad=$ The wavelength of laser light $(632.8 \mathrm{~nm})$

The structural properties of the films were characterized by X-Ray Diffraction (XRD) using Philips $\mathrm{PW} 1840$ diffractometer with $\mathrm{Cu} \mathrm{K} \cdot$ radiation $(\bullet=1.5406$ A) operated at $40 \mathrm{kV}$ and $30 \mathrm{~mA}$. All samples were scanned in the range $\left(20-70^{\circ}\right)$ with a scan speed of $5 \% \mathrm{~min}$. Surface studies of the samples were done with the help of
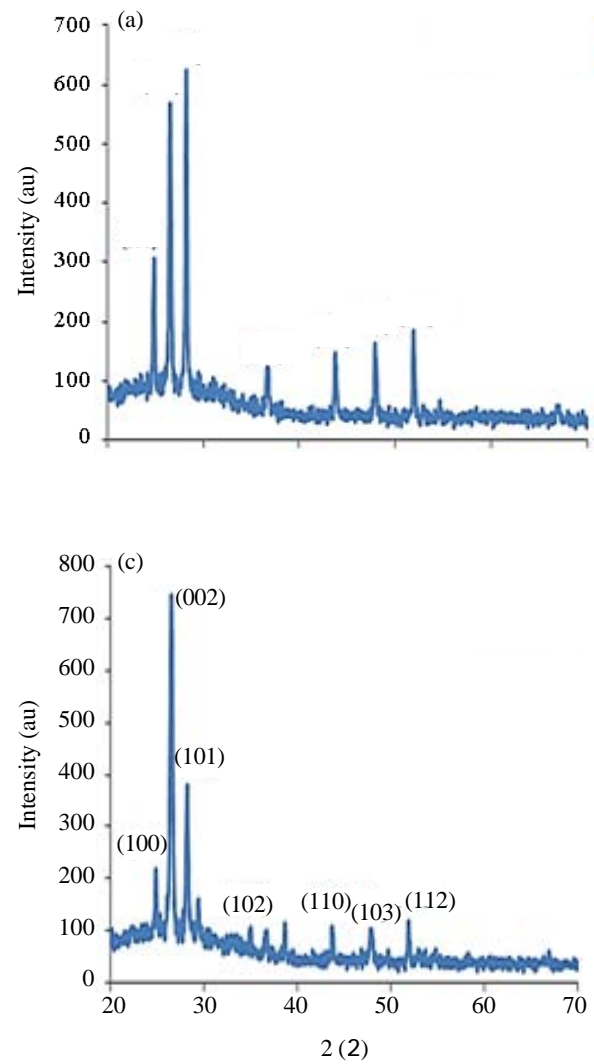

Atomic Force Microscopy (AFM) type (SPM-AA3000 contact mode spectrometer, Angstrom). Optical transmission and absorption spectra of the films were recorded in the wavelength range of (370-1100 nm) using UV-VIS-NIR spectrophotometer (type Shimadzu).

The gas sensing properties of the films at different concentration (10-30 ppm) of ethanol were evaluated at various operating temperatures in the range of $70-400^{\circ} \mathrm{C}$ by measuring the changes of resistance of the films in air and in the gas ethanol. The resistance was measured using Keithley 6514 electrometer.

\section{RESULTS AND DISCUSSION}

Figure 1 shows, the X-ray diffraction patterns for $\mathrm{CdS}$ thin films deposited at $430^{\circ} \mathrm{C}$ with different thicknesses (300-600 nm). From Fig. 1 it can be seen that all films show the diffraction peaks from $(100),(002),(101)$, (102), (110), (103), (112) planes which correspond to hexagonal structure of polycrystalline CdS. No diffraction peaks from other impurities were found, indicating the high purity of the samples. Also, it can be seen that the
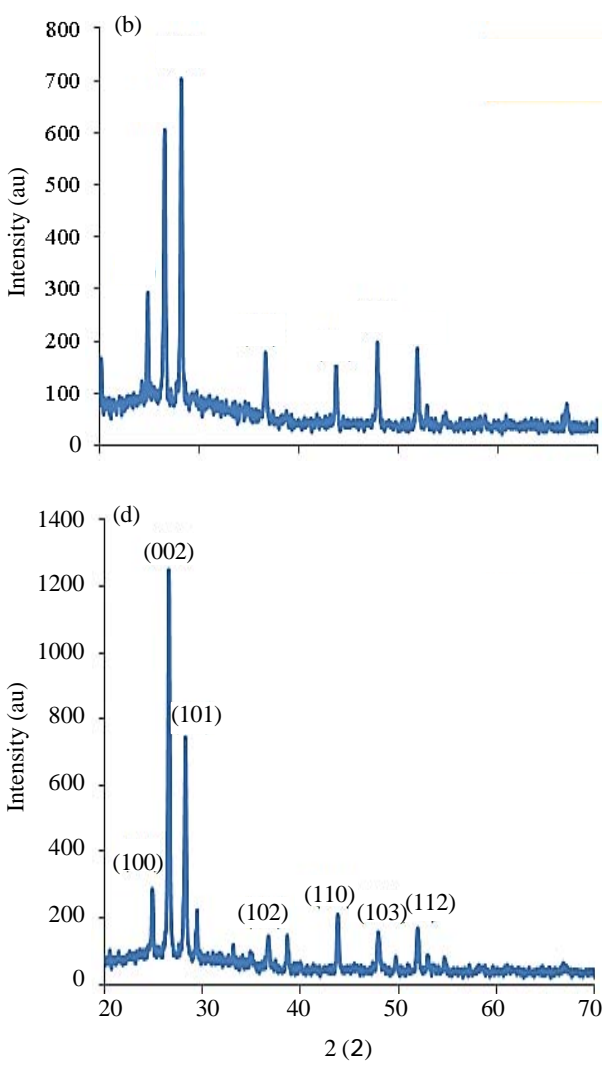

Fig. 1: XRD of CdS thin films at different thickness: a) CdS $300 \mathrm{~nm}$; b) CdS $400 \mathrm{~nm}$; c) CdS $500 \mathrm{~nm}$ and d) CdS $600 \mathrm{~nm}$ 
(101) diffraction peak is predominate in thickness (300 and $400 \mathrm{~nm}$ ). However as the film thickness increased (500 and $600 \mathrm{~nm})$ the $(002)$ diffraction peak is predominant, this means that the c-axis of the CdS films changed from inclined to the substrate to perpendicular to the substrate. These results imply that the mechanism of preferred orientation development changed with increasing thickness.

The values of lattice constants a and c are calculated using Eq. 1) and listed in Table 1, the result showed that the all values are agreement with standard JCPDS card No. 41-1049 (Macleod, 2001).

Table 1: Structural parameters of CdS films from ray diffraction measurements

\begin{tabular}{|c|c|c|c|c|}
\hline \multirow{2}{*}{$\begin{array}{l}\text { Sample thickness } \\
(\mathrm{nm}) /(\mathrm{hkl})\end{array}$} & \multirow[b]{2}{*}{$\mathrm{d}(\AA)$} & \multicolumn{3}{|l|}{ Lattice } \\
\hline & & $\mathrm{a}_{0}$ & $\mathrm{c}_{0}$ & $\mathrm{G}(\mathrm{nm})$ \\
\hline \multicolumn{5}{|l|}{300} \\
\hline$(002)$ & 3.35661 & 4.131 & 6.72 & 50.67 \\
\hline (101) & 3.15754 & & & \\
\hline$(100)$ & 3.57727 & & & \\
\hline \multicolumn{5}{|l|}{400} \\
\hline$(002)$ & 3.35292 & 4.130 & 6.705 & 27.35 \\
\hline (101) & 3.15754 & & & \\
\hline$(100)$ & 3.57834 & & & \\
\hline \multicolumn{5}{|l|}{500} \\
\hline$(002)$ & 3.35524 & 4.143 & 6.713 & 35.55 \\
\hline (101) & 3.15914 & & & \\
\hline$(100)$ & 3.57834 & & & \\
\hline \multicolumn{5}{|l|}{600} \\
\hline$(002)$ & 3.34821 & 4.126 & 6.694 & 56.68 \\
\hline (101) & 3.15287 & & & \\
\hline$(100)$ & 3.57098 & & & \\
\hline
\end{tabular}

(a)

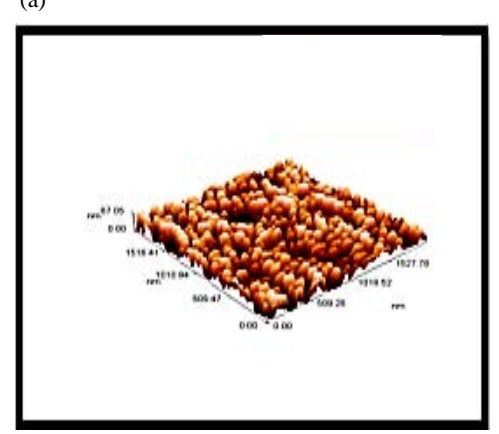

(c)

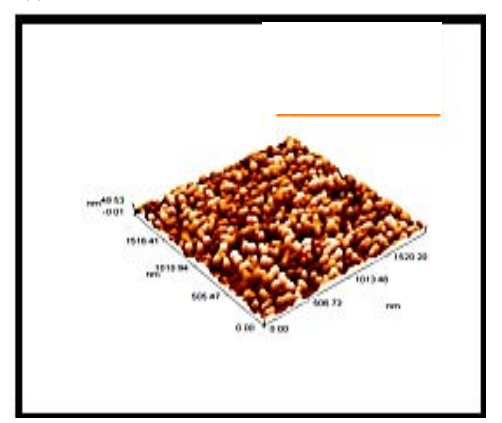

$$
\frac{1}{\mathrm{~d}^{2}}=\frac{4}{3}\left(\frac{\mathrm{h}^{2}+\mathrm{hk}+\mathrm{k}^{2}}{\mathrm{a}^{2}}\right)+\frac{1^{2}}{\mathrm{c}^{2}}
$$

The crystallite size $(\mathrm{G})$ of the films calculated from the highest peak using the following relation (Debye-Scherer formula) (Hazaa, 2015):

$$
\mathrm{G}=\frac{0.9 \lambda}{\beta \cos \theta}
$$

Where:

- $=$ The wavelength of X-rays which is $=1.5406 \AA$

- = The Full Width at Half Maximum (FWHM) measured in radians

- $=$ The Bragg angle

Atomic Force Microscopy (AFM): Figure 2 shown the images (AFM) of CdS thin films for different thickness on the glass substrate at temperature $\left(430^{\circ} \mathrm{C}\right)$, Table 2 shown the Root Mean Square (RMS), roughness and grain size different with films thickness. The grain size range values between (56.68-84.12 nm) these values indicate of increase surface roughness comfort into increase the size of all crystalline (Sagar et al., 2005).

Table 2: The result from the AFM of CdS different thickness
\begin{tabular}{lccc}
\hline Sample thickness (nm) & Roughness (nm) & RMS (nm) & Grain size(nm) \\
\hline 300 & 17.4 & 19.8 & 63.42 \\
400 & 14.2 & 16.6 & 74.47 \\
500 & 10.4 & 12.3 & 56.68 \\
600 & 10.5 & 13.6 & 84.12 \\
\hline
\end{tabular}

(b)

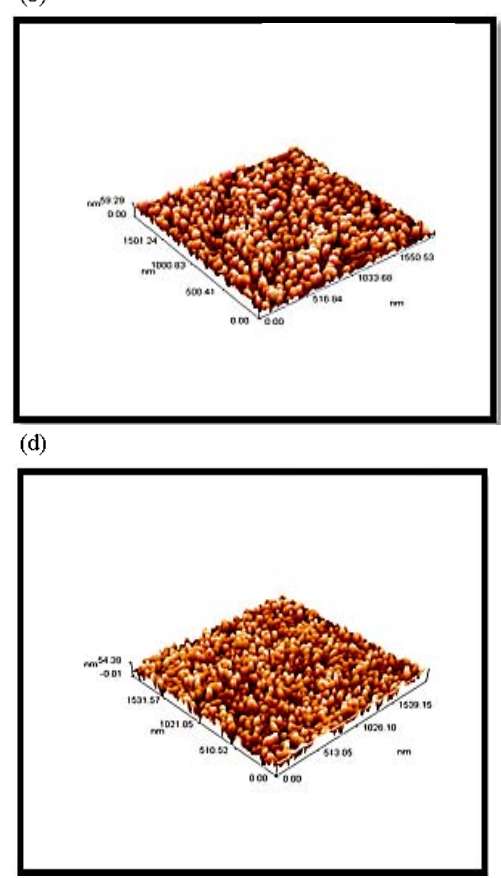

Fig. 2: AFM images for CdS films at different thickness: a) $\mathrm{t}=300 \mathrm{~nm}$; b) $\mathrm{t}=400 \mathrm{~nm}$; $) \mathrm{t}=500 \mathrm{~nm}$ and d) $\mathrm{t}=600 \mathrm{~nm}$ 


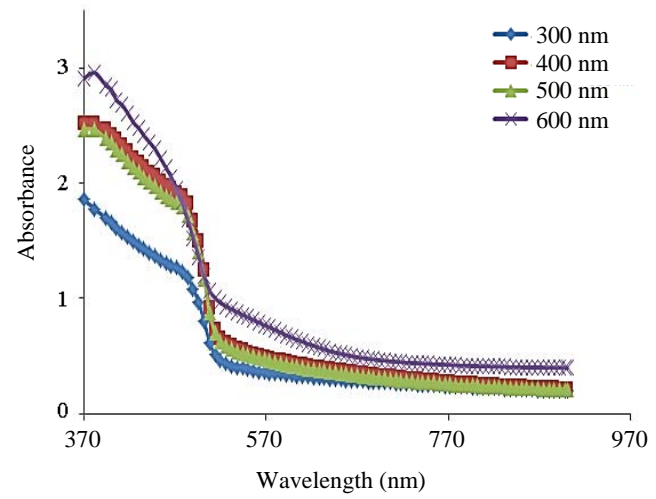

Fig. 3: Transmittance as a function of wavelength at different thickness (CdS)

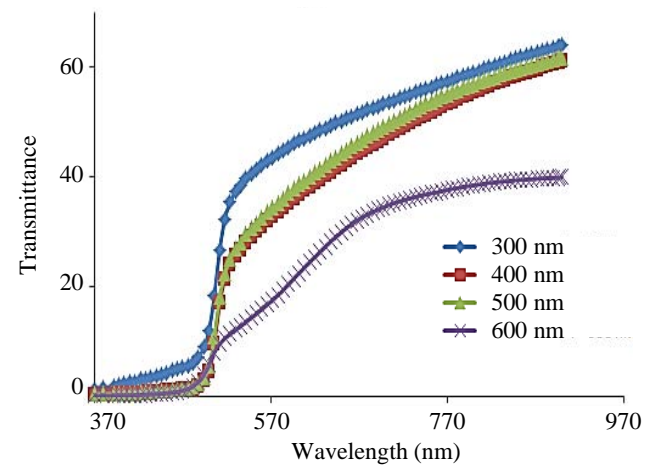

Fig. 4: Absorbance as a function of wavelength at different thickness (CdS)

Optical properties: The optical properties of all films with different thicknesses (300-600 $\mathrm{nm}$ ) have been determined by using Transmittance (T) and Absorbance (A) spectrum in the region ( $370-1100 \mathrm{~nm}$ ). Figure 3 and 4 show, that the transparency decreases and absorbance increases as the thickness increase may due to thickness or to absorption coefficient. The absorption coefficient $(\bullet)$ which is a function of the photon energy $(h v)$ is calculated from the optical transmittance spectra results using the following Eq. 4 (Al-Hamdani and Salih, 2012):

$$
\alpha=(1 / \mathrm{t}) \operatorname{in}(1 / \mathrm{T})
$$

All the films as shown in Fig. 5 had high absorption coefficient $\left(>10^{5} \mathrm{~cm}^{-1}\right)$ above the fundamental absorption edge, indicates the existence allowed transitions and the absorption coefficient increase as the thickness increase. The optical band gap was calculated using following (Cheng and Conibeer, 2011):

$$
\alpha \mathrm{h} \bullet=B\left(h \cdot-E_{g}\right)^{r}
$$

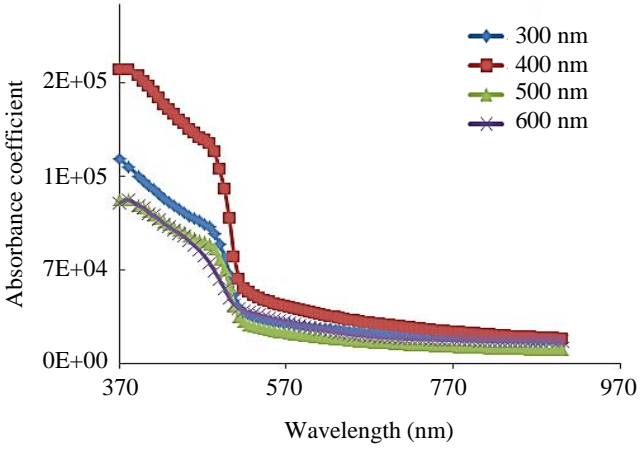

Fig. 5: Absorption coefficient as a function of wavelength at different thickness $(\mathrm{CdS})$

\begin{tabular}{lc} 
Table 3: Optical band gap for CdS films with different thickness & \\
\hline Thickness (nm) & $\mathrm{E}_{g}(\mathrm{eV})$ \\
\hline 300 & 2.35 \\
400 & 2.40 \\
500 & 2.38 \\
600 & 2.42 \\
\hline
\end{tabular}

Where:

$\mathrm{h} \cdot=$ The photon energy

$\mathrm{E}_{\mathrm{g}}=$ The optical band gap

$\mathrm{B}=\mathrm{A}$ constant

$\mathrm{r}=$ The $1 / 2,3 / 2,2$ or 3 for direct allowed, direct forbidden, indirect allowed and indirect forbidden transitions, respectively

A satisfactory linear fit is obtained for $(\bullet h \bullet)^{2}$ vs. $h \bullet$, indicating the presence of direct allowed transition for thin films. The intercept on the energy axis as shown in Fig. 6, give the optical band gap $\mathrm{E}_{\mathrm{g}}$ of the material and listed in Table 2 which are related to the variation of films structures. These values of optical band gap are comparable with the reported value for $\mathrm{CdS}$ thin films (Khallaf et al., 2008; Mona, 2010; Hasnat and Podder, 2013) (Table 3).

Figure 7 and 8 show, the resistance variation with operating temperature of $\mathrm{CdS}$ films for different thickness in air and in ethanol gas, respectively. There is a decrease in resistance with increase in temperature indicating semiconducting behavior and the resistance of CdS film samples upon exposer to ethanol gas was lower than that in air because reduction nature of ethanol gas which is attributed to the decrease in potential barrier at grain boundaries, this result is agreement with other (Raut et al., 2013). The Sensitivity (S) of the sensor toward ethanol gas was measured by using the following relation (Al-Janaby and Al-Jumaili, 2016).

$$
\mathrm{S}=\frac{\mathrm{R}_{\mathrm{a}}-\mathrm{R}_{\mathrm{g}}}{\mathrm{R}_{\mathrm{a}}} \times 100 \%
$$



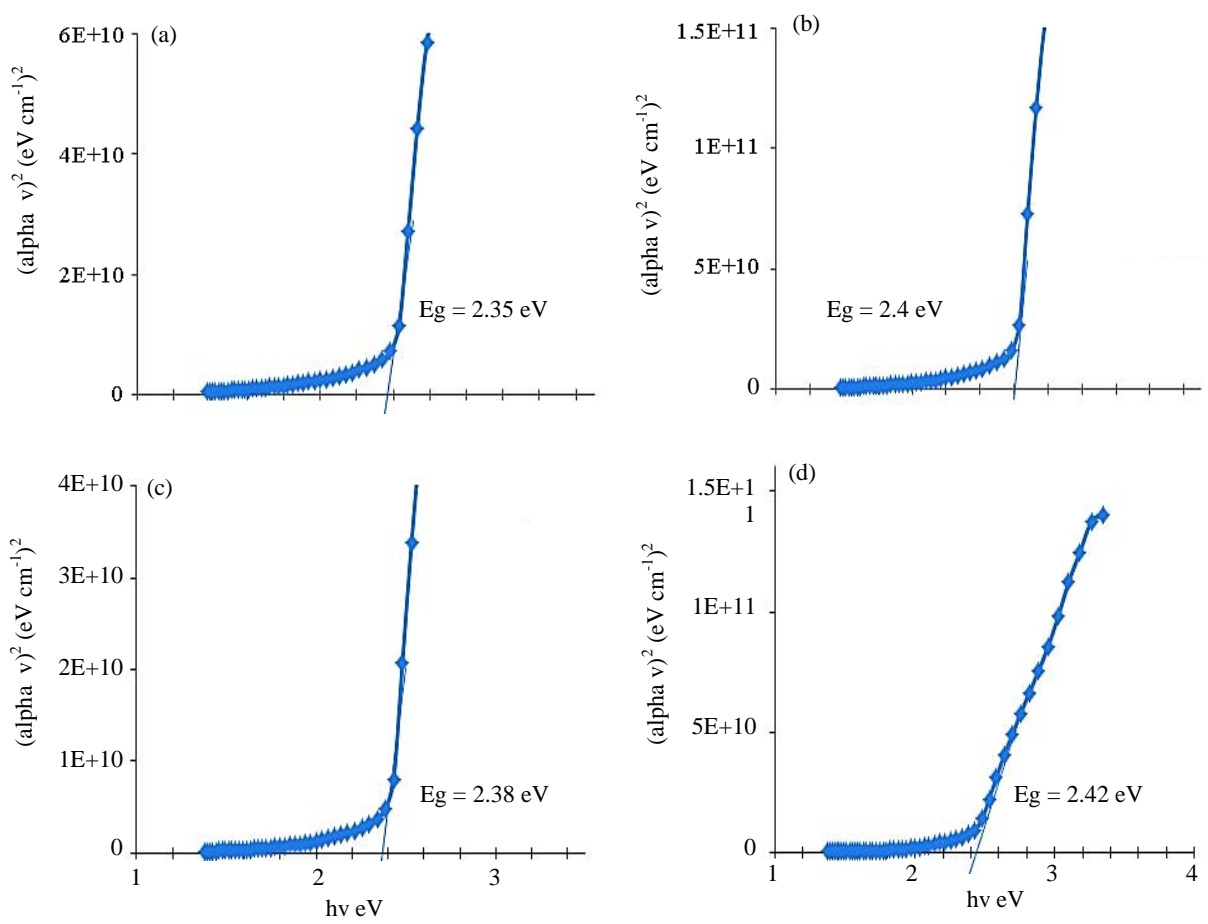

Fig. 6: $(\bullet h \bullet)^{2}$ vs. photon energy for CdS films with different thickness: a) $\left.\left.t=300 \mathrm{~nm} ; \mathrm{b}\right) \mathrm{t}=400 \mathrm{~nm} ; \mathrm{c}\right) \mathrm{t}=500 \mathrm{~nm}$ and d) $\mathrm{t}=600 \mathrm{~nm}$

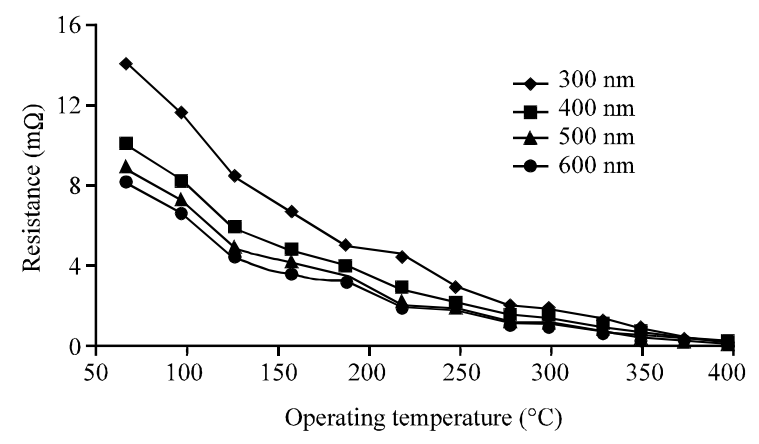

Fig. 7: Resistance vs. operating temperature in air

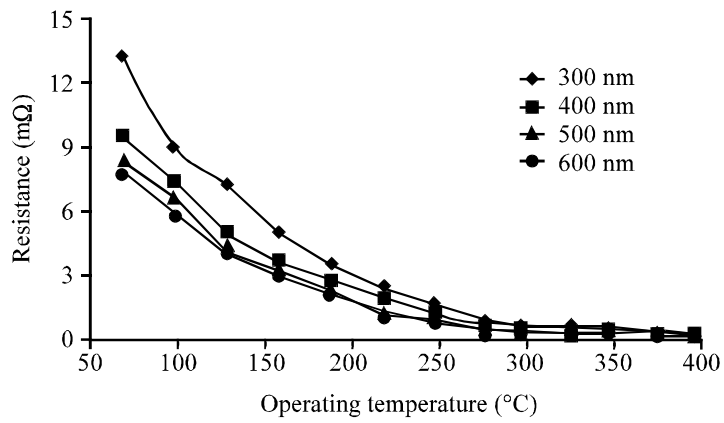

Fig. 8: Resistance vs. operating temperature in $20 \mathrm{ppm}$ ethanol

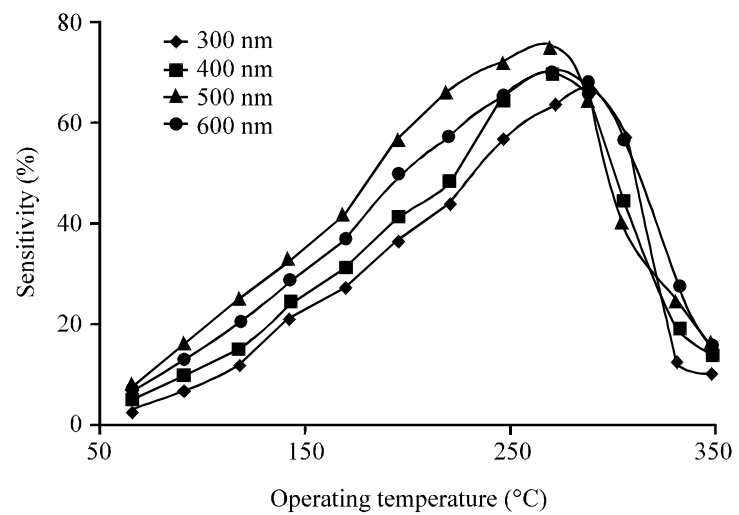

Fig. 9: Sensitivity vs. operating temperature for $20 \mathrm{ppm}$ ethanol

Where:

$\mathrm{R}_{\mathrm{a}}=$ The Resistance of the film in air

$\mathrm{R}_{\mathrm{g}}=$ The Resistance of film upon exposure to ethanol

Figure 9 and 10 shows the sensitivity as functions of operation temperature CdS thin films exposed to $20 \mathrm{ppm}$ ethanol gas concentration with noble metal with different film thickness. For all the samples the sensitivity increases with increase in operating temperature and reach maximum $(\mathrm{S}=75$ for sample with thickness $500 \mathrm{~nm})$ at $310^{\circ} \mathrm{C}$. 


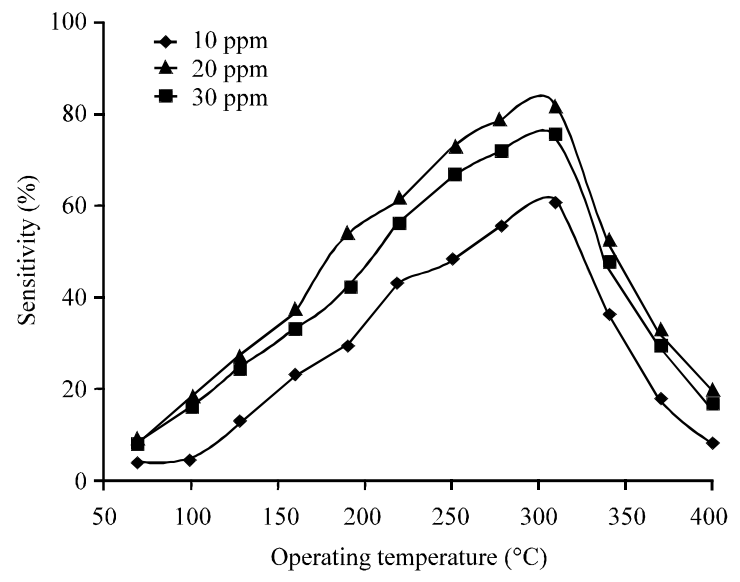

Fig. 10: Sensitivity vs. operating temperature with different ethanol concentration $(\mathrm{t}=500 \mathrm{~nm})$

Response of sensors depends on two factors, the speed of chemical reaction on the surface of the grains, the speed of the diffusion of gas molecules to that surface. At low temperatures the sensor response is restricted by the speed of chemical reactions. At higher temperature the sensor response is restricted by the speed of the diffusion of gas molecules to that surface. At some intermediate temperature the speed values of two processes become equal and at that point the sensor response reaches its maximum. According to this mechanism for every gas there is a specific temperature at which the sensor response attains its peak value (Ramesh et al., 2014).

The response time of the sensor is usually defined as the time taken to achieve at least $90 \%$ of the final change in its sensitivity during exposure to the tested gas. While the recovery time is generally, defined as the time taken by the sensor to get back at least $90 \%$ of its original state after exposure to air by maintaining the operating temperature constant (Dhahri et al., 2017).

The variation of the sensitivity with time of CdS sensors (thickness $500 \mathrm{~nm}$ ) at $310^{\circ} \mathrm{C}$ after exposure to 20 ppm ethanol gas is shown in Fig. 11. It was found that the response time was $11 \mathrm{sec}$ while recovery time was $20 \mathrm{sec}$.

It was observed from Fig. 12 that the response times and recovery times depended on the operating temperature. Both the response times and recovery times were found to shorten at higher operating temperatures. This is may be due to the fact that at higher temperature, the speed of the surface reaction increases because of sufficient thermal energy of the sensor material. However, the response time was found to be shorter than the

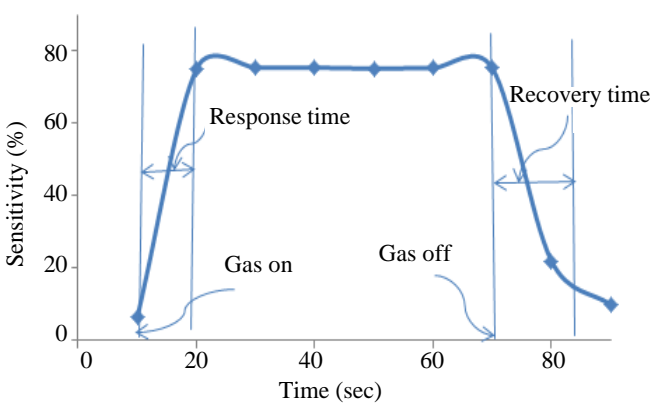

Fig. 11: Sensitivity with response time and recovery time of $\mathrm{CdS}\left(\mathrm{CdS} 20 \mathrm{ppm}\right.$ ethanol at $\left.310^{\circ} \mathrm{C}\right)$

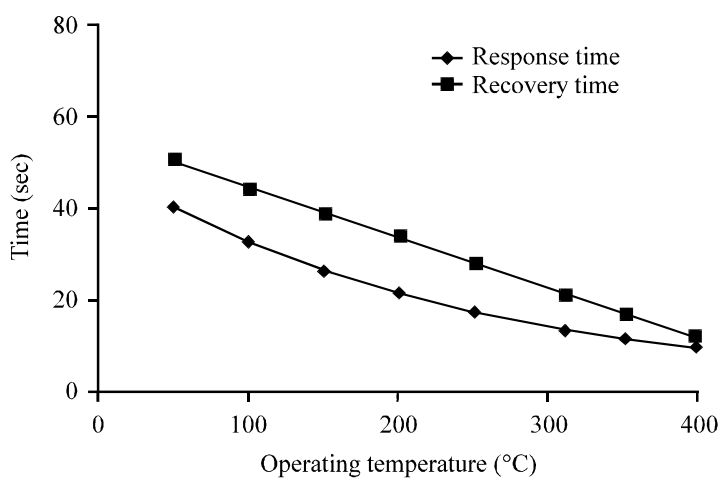

Fig. 12: Dependence of response and recovery time on operating temperature $(20 \mathrm{ppm})$

recovery time at all operating temperature. In this research, the response time and recovery time were found to be 10 and $15 \mathrm{sec}$, respectively at $400^{\circ} \mathrm{C}$ higher operating temperature.

\section{CONCLUSION}

CdS thin films with various thickness was grown successfully via. Ultrasonic Nebulizer Deposition (UND) technique. All films represented hexagonal structure of polycrystalline $\mathrm{CdS}$ with the band gap values of $2.35-2.42 \mathrm{eV}$. The optimum film thickness and operating temperatures are found to be $500 \mathrm{~nm}$ and $310^{\circ} \mathrm{C}$, respectively and with fast response and recovery time were found to be 10 and $15 \mathrm{sec}$, respectively, at $400^{\circ} \mathrm{C}$ operating temperature.

\section{REFERENCES}

Al-Hamdani, N.A. and A.A.H. Salih, 2012. Preparation of nanocrystalline copper doped CdS thin films by spray pyrolysis method. Diyala Pure Sci., 8: 285-295. 
Al-Janaby, A.Z. and H.S. Al-Jumaili, 2016. Structural, optical and sensitive properties of Ag-Doped tin oxide thin films. Intl. Res. J. Eng. Technol., 3: 40-45.

Chander, S. and M.S. Dhaka, 2017. Optical and structural constants of CdS thin films grown by electron beam vacuum evaporation for solar cells. Thin Solid Films, 638: 179-188.

Cheng, S. and G. Conibeer, 2011. Physical properties of very thin $\mathrm{SnS}$ films deposited by thermal evaporation. Thin Solid Films, 520: 837-841.

Dhahri, R., M. Hjiri, L. El Mir, H. Alamri and A. Bonavita et al., 2017. CO sensing characteristics of In-doped $\mathrm{ZnO}$ semiconductor nanoparticles. J. Sci. Adv. Mater. Devices, 2: 34-40.

Hasnat, A. and J. Podder, 2013. Optical and electrical characteristics of pure CdS thin films for different thickness. J. Bangladesh Acad. Sci., 37: 33-41.

Hazaa, S.K., 2015. Effect of post annealing on structural and optical propertie of $\mathrm{SnO} 2$ thin films deposited by DC magnetron sputtering. J. Appl. Phys., 7: 59-63.

Khallaf, H., G. Chai, O. Lupan, L. Chow and S. Park et al., 2008. Investigation of aluminium and indium in situ doping of chemical bath deposited CdS thin films. J. Phys. D. Appl. Phys., 41: 1-5.

Kumar, C.K., N.T.Q. Hoa, S.G. Yoon, E.T. Kim and J.H. Lee et al., 2009. Highly photoconductive CDs thin films synthesized by using chemical bath deposition. J. Korean Phys. Soc., 55: 284-287.
Li, M., W. Ren, R. Wu and M. Zhang, 2017. $\mathrm{CeO}_{2}$ enhanced ethanol sensing performance in a CdS gas sensor. Sens., 17: 1577-1584.

Macleod, H.A., 2001. Thin Film Optical Fillers. 3rd Edn., Taylor and Francis, Milton Park, Didcot, England,

Mathew, X., J.P. Enriquez, A. Romeo and A.N. Tiwari, 2004. $\mathrm{CdTe} / \mathrm{CdS}$ solar cells on flexible substrates. Solar Energy, 77: 831-838.

Mona, M.S., 2010. Structural and optical properties of CdS:20\%In films prepared by thermal Co-evaporation method. J. Sci. Baghdad, 2: 1355-1359.

Nesheva, D., Z. Aneva, S. Reynolds, C. Main and A.G. Fitzgerald, 2006. Preparation of micro-and nanocrystalline CdSe and CdS thin films suitable for sensor applications. J. Optoelectron. Adv. Mater., 8: 2120-2125.

Ramesh, H.B., B.P. Sharad and R.B. Anil, 2014. Synthesis, characterization and gas sensing performance of sol-gel prepared nonocrystalline $\mathrm{SnO} 2$ thin films. Intl. J. Smart Sens. Intell. Syst., 7: 610-629.

Raut, B.T., P.R. Godse, S.G. Pawar, M.A. Chougule and D.K. Bandgar et al., 2013. Development of nanostructured CdS sensor for H2S recognition: Structural and physical characterization. J. Exp. Nanosci., 8: 876-889.

Sagar, P., M. Kumar and R.M. Mehra, 2005. Electrical and optical properties of sol-gel derived $\mathrm{ZnO}: \mathrm{Al}$ thin films. Mater. Sci.-Poland, 23: 685-696.

Williams, B.L., J.D. Major, L. Bowen, L. Phillips and G. Zoppi et al., 2014. Challenges and prospects for developing $\mathrm{CdS} / \mathrm{CdTe}$ substrate solar cells on Mo foils. Solar Energy Mater. Solar Cells, 124: 31-38. 